\title{
Treatment of Intractable Diabetic Macular Edema with Pegaptanib Versus Bevacizumab, Both in Combination with Dexamethasone
}

Diana M. Leitner, M.D. ${ }^{1}$, David M. Chacko, M.D., Ph.D. ${ }^{1,2}$, Philip Twumasi-Ankrah, Ph.D. ${ }^{3}$, Elizabeth Ablah, Ph.D., M.P.H. ${ }^{3}$

${ }^{1}$ University of Kansas School of Medicine-Wichita

Department of Internal Medicine

${ }^{2}$ Grene Vision Group, Wichita, KS

${ }^{3}$ University of Kansas School of Medicine-Wichita

Department of Preventive Medicine and Public Health

\begin{abstract}
Background. Diabetic macular edema is a significant cause of vision loss, and some patients do not respond optimally to existing treatments. This study compared the response of intractable diabetic macular edema to intravitreal injection of two anti-VEGF drugs, bevacizumab and pegaptanib, both in combination with dexamethasone.

Methods. A retrospective chart review was conducted to examine patients from an ophthalmology practice in one year with diabetic macular edema (DME), recurrent or persistent, after focal laser or intravitreal bevacizumab. Patients received bevacizumab/dexamethasone or pegaptanib/dexamethasone. Outcome measures were improvement in best corrected visual activity (converted to LogMAR) and central macular thickness (CRT). Data on adverse effects also were collected.

Results. The bevacizumab/dexamethasone group included 25 eyes which had pre-treatment $\operatorname{LogMAR}=0.69 \pm 0.49$ (mean $\pm \mathrm{SD}$ ) and CRT $=419 \pm 131$. Post-treatment LogMAR was $0.70 \pm$ 0.48 and CRT $=377 \pm 107$. The pegaptanib/dexamethasone group included 14 eyes; pretreatment $\operatorname{LogMAR}=0.80 \pm 0.55$ and CRT $=520 \pm 108$. Post-treatment LogMAR was $0.77 \pm$ 0.49 and CRT $=464 \pm 106$. Neither treatment had a significant effect on visual acuity. Both groups experienced a significant decrease in CRT over time $(\mathrm{p}=0.006)$. The pegaptanib/ dexamethasone group had higher CRT at all times $(\mathrm{p}=0.020)$, but the trend in CRT decrease was not different between the two groups. Intraocular pressure increased in both groups $(\mathrm{p}=$ 0.038). No other adverse effects were reported.

Conclusions. Neither bevacizumab/dexamethasone or pegaptanib/dexamethasone significantly improved visual acuity in intractable DME, but both decreased central macular thickness. Differences in outcome measures between the two treatment groups were not significant. The only adverse effect seen was a small increase in intraocular pressure.
\end{abstract}

KS J Med 2012; 5(3):83-93.

\section{Introduction}

Diabetic retinopathy occurs in approximately $29 \%$ of persons with diabetes mellitus and is severe enough to threaten vision among $4.4 \% .^{1-3}$ Diabetic macular edema (DME) is a type of retinopathy resulting from microvascular damage to retinal capillaries, causing breakdown of the blood-retinal barrier and allowing leakage into the retina. ${ }^{4-5}$ The resulting edema causes damage which can impair visual acuity and may result in blindness. ${ }^{6-7}$ The prevalence of DME in diabetic patients varies from $0.9 \%$ to $29 \% .^{8-10}$ Diabetic retinopathy is the leading cause of new onset blindness among Americans 20 to 74 years old ${ }^{1}$ and accounts for $4.8 \%$ of blindness worldwide. ${ }^{11}$ 
Treatment for diabetic macular edema is complex, controversial, and changing. Laser photocoagulation with a focal/grid laser can decrease vision loss from DME, ${ }^{12-14}$ however, a number of patients fail to respond optimally to laser treatment. Inflammatory processes may be an important component of retinal damage in DME, ${ }^{15}$ which has led to investigation of intravitreal corticosteroids as a possible treatment. $^{16-18}$ Studies suggest intravitreal dexamethasone improves visual acuity and central macular thickness. ${ }^{19,20}$ Adverse effects of intravitreal steroids include glaucoma and cataract formation. ${ }^{21-22}$

Vascular endothelial growth factor (VEGF) is another proposed culprit for damage in DME, possibly via increased vascular permeability and action as a proinflammatory mediator. ${ }^{23,24}$

Bevacizumab $\quad$ Avastin $\left._{\circledast}\right)_{\text {) }}$ is a recombinant humanized antibody that targets many VEGF isoforms. ${ }^{25}$ Intravitreal bevacizumab is used off-label for DME. ${ }^{26-31}$ Adverse effects of intravitreal bevacizumab include anterior chamber reactions from injection, increased intraocular pressure, endophthalmitis, and rare systemic effects. ${ }^{27,32-34}$

Pegaptanib (Macugen ${ }_{\circledast}$ ) is a pegylated aptamer that binds and neutralizes primarily the 165-isomer of VEGF. It is approved for intravitreal use and is used off-label for DME. ${ }^{35-37}$ Possible adverse effects of intravitreal pegaptanib treatment include endophthalmitis, retinal detachment, and traumatic cataracts. ${ }^{38-40}$ Research has not determined the ideal treatment algorithm for diabetic macular edema and the role of antiVEGF therapies. ${ }^{41}$

No studies have been published comparing the efficacy of bevacizumab and pegaptanib. These two anti-VEGF agents have slightly different structures and mechanisms of action and bevacizumab is significantly less expensive than pegaptanib.
Additionally, no published studies have examined the efficacy of combination therapy with dexamethasone and anti-VEGF drugs. This study was designed to compare the efficacy of combined intravitreal treatments of pegaptanib/dexamethasone versus bevacizumab/dexamethasone for intractable DME.

\section{Methods}

Participants. A retrospective chart review was conducted to examine patients with DME in an ophthalmology practice who were treated during the 2010 calendar year with intravitreal bevacizumab/dexamethasone or pegaptanib/dexamethasone. Patients who were diagnosed with severe DME refractory to other treatments including focal laser therapy or intravitreal bevacizumab monotherapy had been offered combined treatment with intravitreal dexamethasone and an anti-VEGF agent.

Instrument. Inclusion criteria included a diagnosis of diabetic macular edema and an intravitreal injection of bevacizumab/dexamethasone or pegaptanib/dexamethasone. Patients who were lost to follow-up within five weeks of treatment were excluded. All eyes which met the inclusion/exclusion criteria were included in the analysis. The following data were collected from patient charts: best corrected visual acuity, central macular thickness measured by ocular coherence tomography (Cirrus HD OCT, Carl Zeiss Meditec, Jena, Germany), and intraocular pressure (Tono-Pen, Reichert Technologies, Depew, New York, USA). Data also were collected on patient demographics, duration of diabetes, and potential adverse effects of the treatment.

Method of Injections. After informed consent, patients were anesthetized with one drop of viscous lidocaine and two sets of proparacaine ophthalmic drops two minutes apart. One minute after the final anesthetic drop, subconjunctival injection of $2 \%$ 
lidocaine with epinephrine was performed. The eye was prepared with topical $10 \%$ Betadine $_{\circledast}$, with application repeated after five minutes. Intravitreal injection was performed with one of the following agents: $1.25 \mathrm{mg}$ bevacizumab, $0.03 \mathrm{mg}$ pegaptanib, or $0.4 \mathrm{mg}$ dexamethasone. Patients were instructed to use polymixin $\mathrm{B} /$ trimethoprim (Polytrim $_{\circledast}$ ) ophthalmic drops four times per day for three days before injections and one week following injections. Patients treated with combined therapy received dexamethasone and an anti-VEGF agent via the same procedure one to six weeks apart. Some patients received additional intravitreal treatments after the conclusion of data gathering, depending on response to treatment.

The clinical endpoints of this study were best corrected visual acuity (BCVA) and central macular thickness (CRT). Visual acuity was measured on the Snellen chart with the patient's current prescription and with a pinhole. When visual acuity improved significantly with the pinhole, this measurement was used as BCVA to decrease refractive error as a source of reduced visual acuity. BCVA was converted to the logarithm of the minimum angle of resolution (LogMAR) for analysis. ${ }^{42}$ Central macular thickness (microns) was measured by ocular coherence tomography; this measurement has been shown to correlate with visual acuity and severity of retinopathy. ${ }^{43}$ Change in intraocular pressure (IOP, measured in $\mathrm{mmHg}$ ) from baseline to extended observation was calculated to evaluate a possible adverse effect of therapy. Data also were collected regarding other possible adverse effects from treatment, as well as diabetes history, patient demographics, and other ocular conditions.

Analysis. Data were collected on pretreatment values, post-treatment values measured at the first visit after combined treatment (generally within several weeks), and extended observation values measured at the last visit of the year (an average of 4.5 months after initial treatment). Changes in clinical endpoints were assessed as the difference between the baseline measurement and the immediate post-treatment measurement. Baseline values for each variable were defined as the last measurement collected prior to intravitreal drug administration. Repeated measures multivariate analysis of variance (rMANOVA) was used to determine statistical significance after Mauchly's test of sphericity determined the appropriate statistical method. $^{44-46} \mathrm{~A}$ p-value less than 0.05 was considered significant.

This project was approved by the Human Subjects Committee at the University of Kansas School of Medicine-Wichita.

\section{Results}

In the 2010 calendar year, 25 eyes were treated with combined bevacizumab/ dexamethasone administered within a 6week period (Table 1). There was large variability in this sample; the average pretreatment LogMAR was $0.69 \pm 0.49$ (mean \pm standard deviation) corresponding to an average visual acuity of 20/98, and average CRT was $419 \pm 131 \mathrm{~nm}$ before treatment (Table 2). Initial post-treatment visual acuity improved in eight eyes $(32 \%)$; decreased visual acuity was seen in seven eyes $(28 \%)$, and 10 eyes (40\%) experienced no change in visual acuity.

Pegaptanib/dexamethasone was used in 14 eyes (Table 1). Average pre-treatment LogMAR was $0.80 \pm 0.55$ corresponding to an average visual acuity of 20/126; pretreatment CRT was $520 \pm 108$ (Table 2). Post-treatment visual acuity improved in five eyes (36\%), four eyes (29\%) experienced decreased visual acuity following treatment, and five eyes (36\%) had no change in visual acuity. 
Table 1 . Bevacizumab and pegaptanib treatment groups.

\begin{tabular}{|l|c|c|c|c|}
\hline & $\begin{array}{c}\text { Number of } \\
\text { Eyes }\end{array}$ & $\%$ Male & $\begin{array}{c}\text { Mean Age } \\
\text { (SD) }\end{array}$ & $\begin{array}{c}\text { Mean Duration of } \\
\text { Diabetes } \\
\text { (SD) }\end{array}$ \\
\hline Bevacizumab/dexamethasone & 25 & $56 \%$ & $68 \pm 10$ & $16 \pm 11$ \\
\hline Pegaptanib/dexamethasone & 14 & $50 \%$ & $70 \pm 11$ & $19 \pm 9$ \\
\hline
\end{tabular}

Table 2. Values and changes in LogMAR (Logarithm of Minimum Angle of Resolution), Central Macular Thickness (CRT), and Intraocular Pressure (IOP).

\begin{tabular}{|l|c|c|c|c|c|c|}
\hline & $\begin{array}{c}\text { Pre- } \\
\text { treatment } \\
\text { (Mean } \pm \\
\text { SD) }\end{array}$ & $\begin{array}{c}\text { Post- } \\
\text { treatment } \\
\text { (Mean } \pm \\
\text { SD) }\end{array}$ & $\begin{array}{c}\text { Extended } \\
\text { observation } \\
\text { (Mean } \pm \\
\text { SD) }\end{array}$ & $\begin{array}{c}\text { Mean } \\
\text { Change in } \\
\text { LogMAR } \\
\text { (SD) }\end{array}$ & $\begin{array}{c}\text { Mean } \\
\text { Change } \\
\text { in CRT } \\
\text { (SD) }\end{array}$ & $\begin{array}{c}\text { Mean } \\
\text { Change } \\
\text { in IOP } \\
\text { (SD) }\end{array}$ \\
\hline Bevacizumab/ & LogMAR: & LogMAR: & LogMAR: & $0.01 \pm$ & $-42 \pm 96$ & $0.2 \pm 3.5$ \\
dexamethasone & $0.69 \pm 0.49$ & $0.70 \pm 0.48$ & $0.70 \pm 0.50$ & 0.22 & & \\
& CRT: 419 & CRT: 377 & CRT: $391 \pm$ \\
\pm 131 & \pm 107 & 127 & & & \\
\hline $\begin{array}{l}\text { Pegaptanib/ } \\
\text { dexamethasone }\end{array}$ & LogMAR: & LogMAR: & LogMAR: & $-0.03 \pm$ & $-56 \pm 85$ & $3.2 \pm 6.5$ \\
& $0.80 \pm 0.55$ & $0.77 \pm 0.49$ & $0.75 \pm 0.50$ & 0.17 & & \\
& CRT: 520 & CRT: 464 & CRT: $448 \pm$ & & & \\
\hline p-value & \pm 108 & \pm 106 & 133 & & & \\
\hline
\end{tabular}

The pegaptanib group had increased baseline central macular thickness for patient age and diabetes duration (Figure 1).

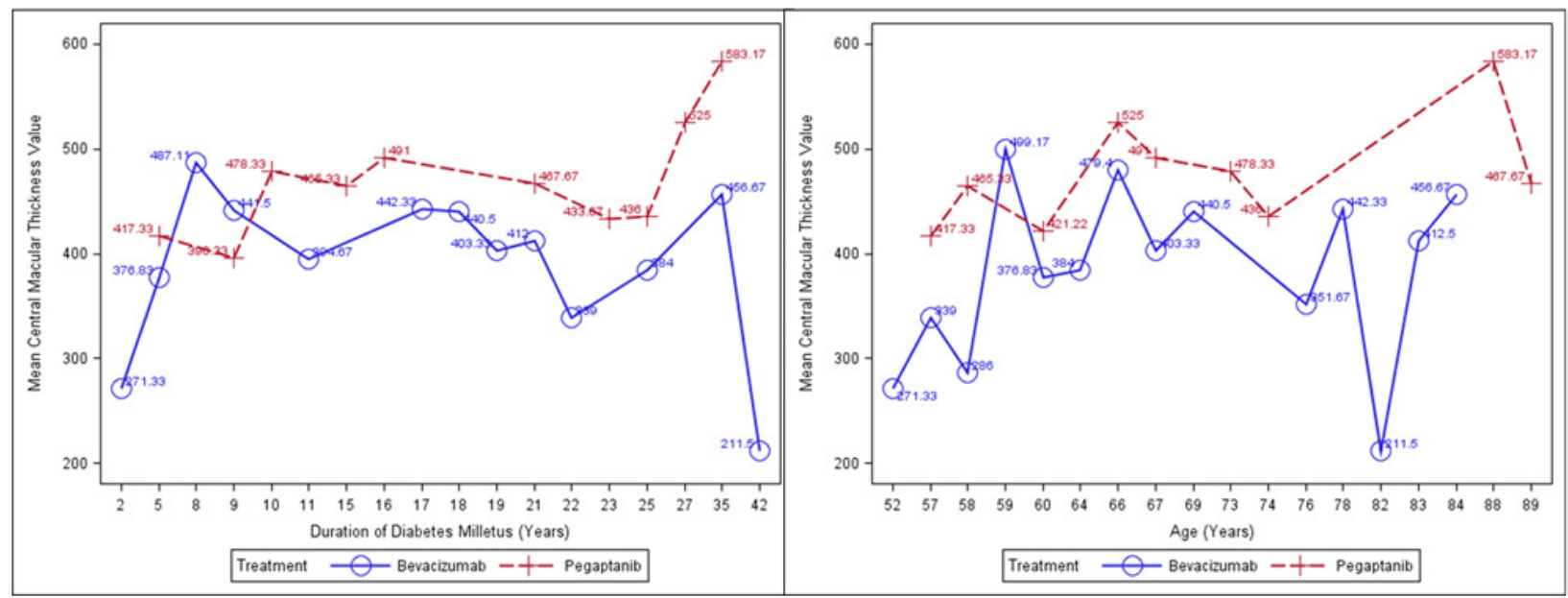

Figure 1. Graph of Central Macular Thickness over Age (right) and Diabetes Duration (left).
However, no trend was seen in the LogMAR data (Figure 2). 

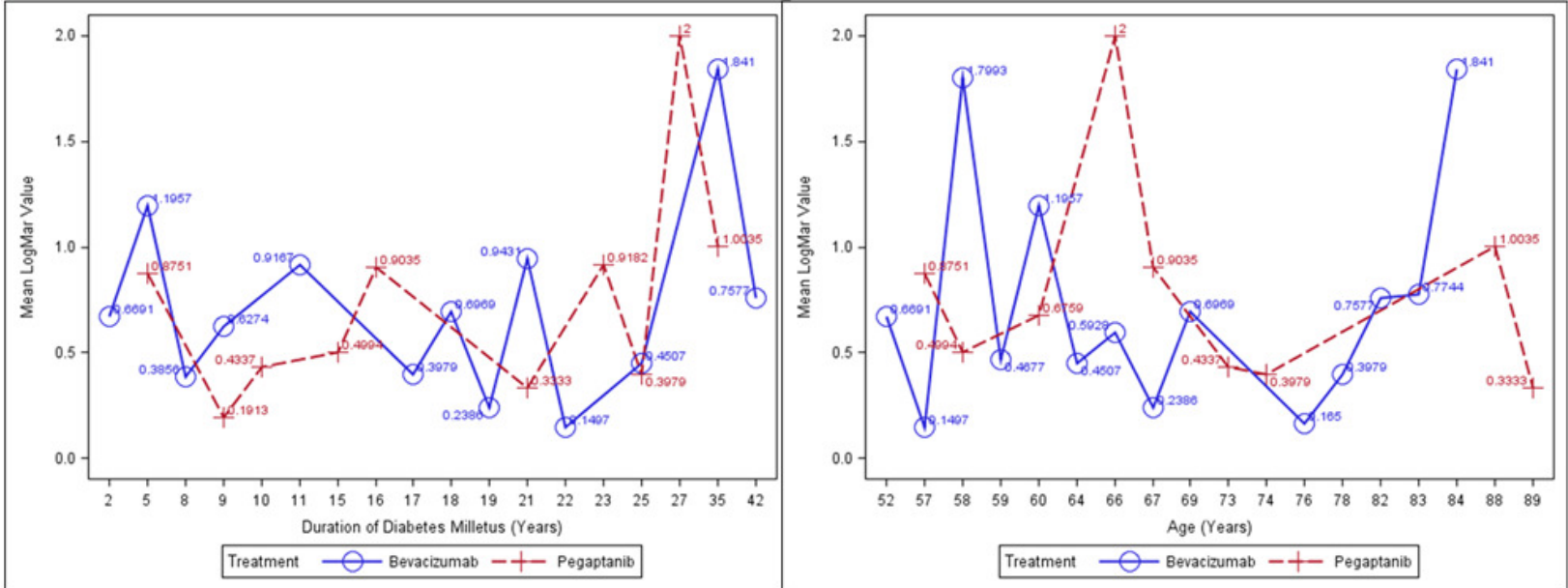

Figure 2. Graph of LogMAR over Age (right) and Diabetes Duration (left).

There were subtle differences between the LogMAR responses in the two treatment groups (Figure 3). Eyes in the pegaptanib group had worse baseline visual acuities and larger LogMAR values, but visual acuity improved over time. In contrast, visual acuity in the bevacizumab group remained relatively stable. However, these differences were not statistically significant. No statistically significant change in LogMAR between pre-treatment, post-treatment, and extended observation occurred in either group. Similarly, there were no differences between the pegaptanib/dexamethasone group and the bevacizumab/dexamethasone group averaged across all observations and over time.

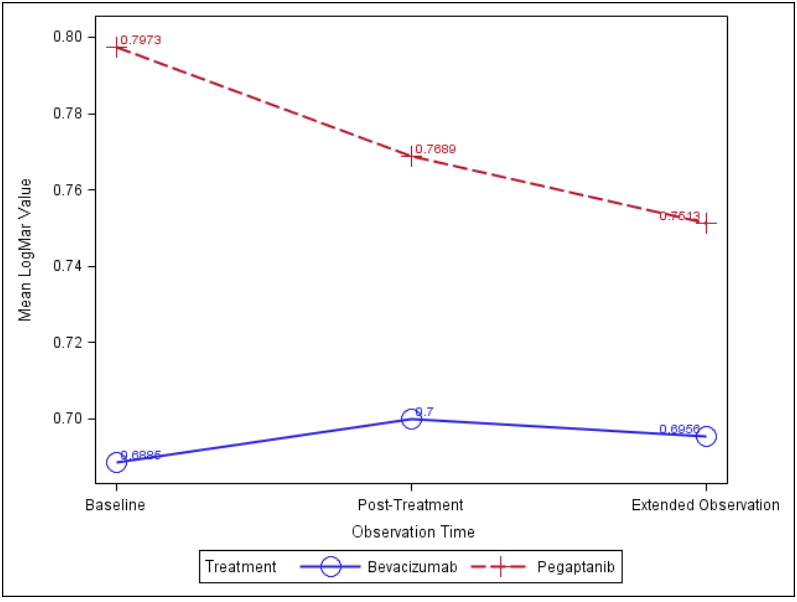

Figure 3. Graph of LogMAR over Time.

Both groups experienced a significant decrease in CRT over time $(\mathrm{p}=0.006$; Figure 4). At all observation points, CRT was higher in the pegaptanib group compared to the bevacizumab group $(\mathrm{p}=$ 0.020). However, the trends of the change in CRT were not significantly different for the bevacizumab and pegaptanib groups (reflected by the parallel lines in the figures). No significant change occurred between pre-treatment and post-treatment measurements or between post-treatment versus extended observation values. 


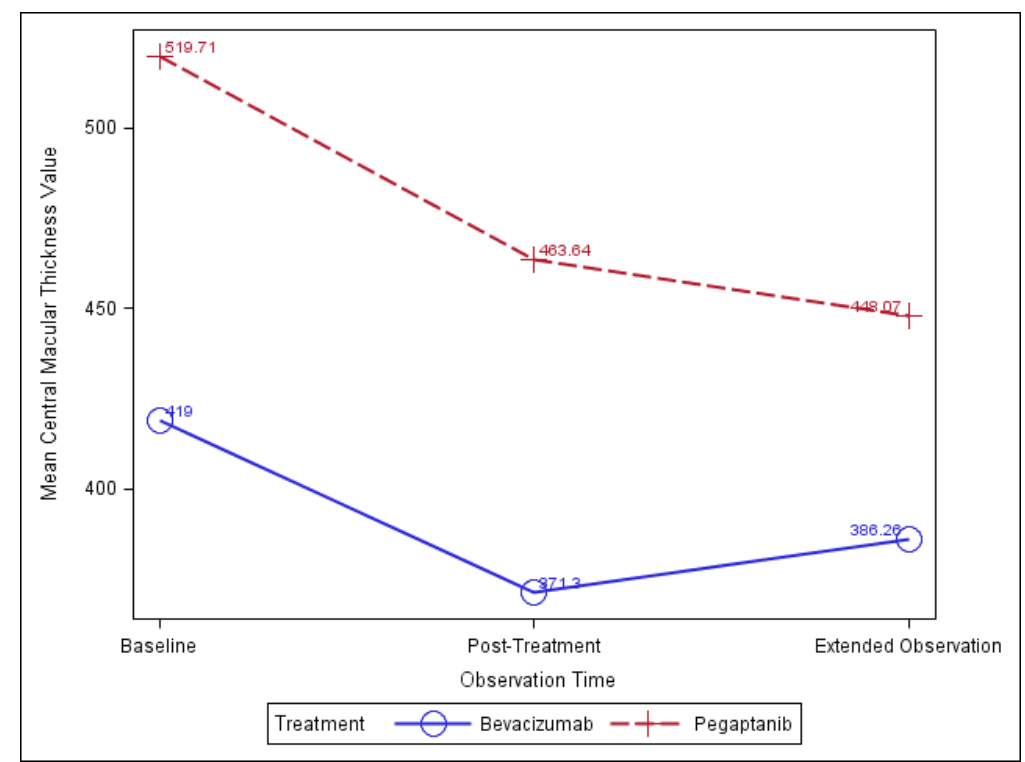

Figure 4. Central Macular Thickness over Time.

Intraocular pressure was measured at baseline and after extended observation to evaluate a possible adverse effect of therapy. A significant increase over time occured ( $p$ $=0.038$; Figure 5). No patients in either treatment group received a new diagnosis of either intraocular hypertension or glaucoma during the course of this study. The pegaptanib group had a greater increase in IOP. The bevacizumab group maintained a more stable IOP, although the change was similar in trend and direction for the two treatment groups. There was no significant difference in IOP between the two groups when averaged over time.

Other than the increase in intraocular pressure, no other complications were reported for any of the eyes in this study. No ocular complications such infections or retinal detachment occured, and no systemic events such as myocardial infarction or cerebrovascular events were reported.

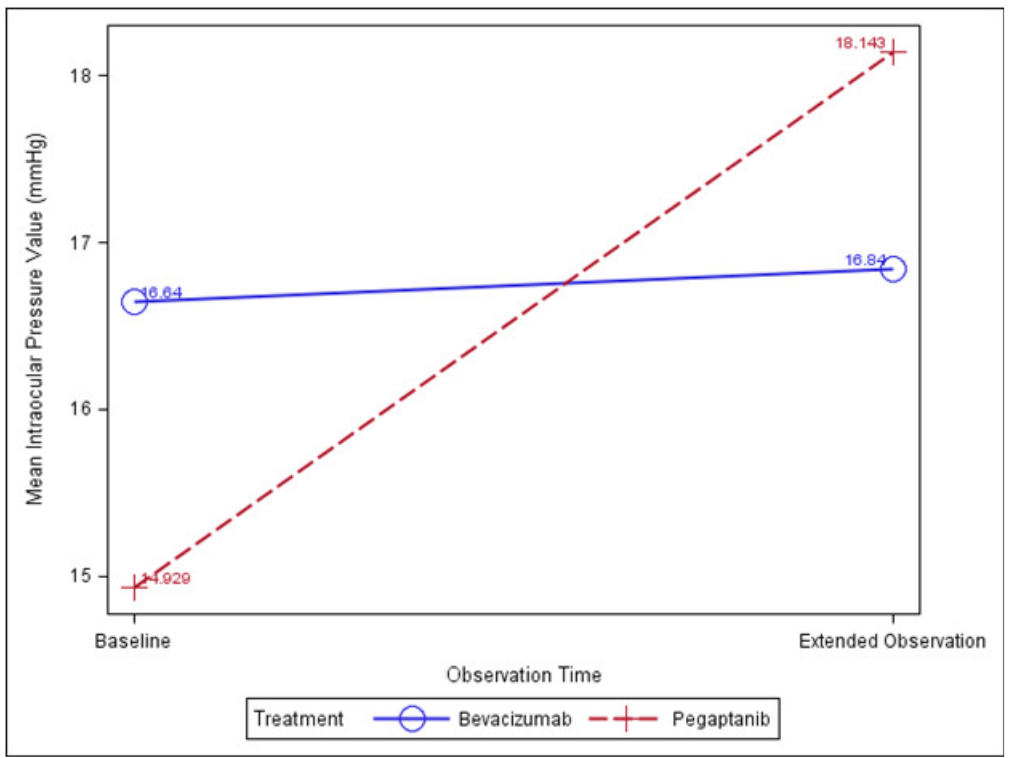

Figure 5. Graph of Intraocular Pressure over Time. 


\section{Discussion}

There was no significant effect on visual acuity after treatment with either bevacizumab/dexamethasone or pegaptanib/ dexamethasone, and there was no difference in change in visual acuity and central macular thickness between the two treatment groups. Apparently, neither treatment is ideal for refractory diabetic macular edema and new therapies are needed to improve visual acuity. However, patients did not lose visual acuity during the study, so the treatments may have prevented further vision loss. This is difficult to assess in an uncontrolled study.

Significant decrease in central macular thickness occurred in both treatment groups. Persistent macular edema can lead to significant loss of vision in other ocular conditions. ${ }^{47}$ It is possible that the same may hold true for DME, so the reduction in CRT could reduce risk of further retinal damage. Bevacizumab/dexamethasone and pegaptanib/dexamethasone worked equally well to decrease CRT. Although pegaptanib has more restricted anti-VEGF activity compared with bevacizumab (a nonspecific anti-VEGF agent), the two compounds had similar efficacy.

Previous studies have shown treatment with intravitreal bevacizumab improved visual acuity and central macular thickness in new-onset $\mathrm{DME}^{30-31}$ as well as DME persistent after focal laser therapy. ${ }^{26-28}$ Intravitreal pegaptanib also improves visual acuity and central macular thickness for DME $^{37}$ and new-onset DME specifically. ${ }^{36}$ Our study suggested that the benefits of bevacizumab/dexamethasone and pegaptanib/dexamethasone are not as striking in patients with refractory diabetic macular edema who already have failed therapies such as intravitreal bevacizumab. Our study did not address the benefits of therapy in treatment-naïve patients.
The pegaptanib group had increased CRT for demographic variables and over time throughout this study. Although no trend was seen for visual acuity, higher CRT would be expected in more severe disease with increased edema. This may reflect a bias in treatment selection; patients with more severe DME may have been offered pegaptanib more frequently in attempt to preserve vision in DME refractory to other treatments such as bevacizumab monotherapy.

A small increase in intraocular pressure occurred in both the bevacizumab and pegaptanib treatment groups. No eyes in this study received a diagnosis of glaucoma or intraocular hypertension. Although the increase in intraocular pressure was statistically significant, it is not clear whether the small increase is clinically significant. The time of intraocular pressure measurement was not collected, and the normal diurnal variation in intraocular pressure could account for the change. Elevated intraocular pressure with resulting glaucoma has been reported as an important adverse effect of intravitreal steroid treatment with triamcinolone. ${ }^{21-22}$ Our study suggested that dexamethasone may be less problematic than triamcinolone with regard to incidence of glaucoma. Further study on the long-term effects of treatment may clarify this issue.

Aside from the increase in intraocular pressure, no other ocular or systemic adverse effects were seen. There were no reports of endophthalmitis following intravitreal injection. This is noteworthy as there are reports of endophthalmitis following intravitreal bevacizumab, likely due to processing by compounding pharmacies. $^{32,33,48}$ While all data were collected from ophthalmology charts to evaluate adverse effects, complete health 
records were not available. Data on systemic events may not have been available if events were not communicated to the ophthalmologist.

Limitations. This was a small retrospective pilot study with several inherent limitations. This study did not include a control group, and patients were not randomized into treatment groups. It may have been underpowered to detect subtle differences. Pertinent data were unavailable on many patients. For example, visual acuity was measured with a patient's current prescription but refraction was not optimized for the patient at the time of testing. Complete health records were not available, and background information on diabetes such as hemoglobin $\mathrm{A}_{1 \mathrm{c}}$ level was not recorded for many patients, limiting the ability to judge if the two treatment groups were initially equivalent.

Patients were treated with alternating injections of dexamethasone and an antiVEGF agent. The influence of the steroid treatment may make it more difficult to compare pegaptanib to bevacizumab. This study examined patients over the course of one calendar year; extension of this study to examine a longer time frame would give a clearer picture of the duration of treatment effects as well as any adverse effects. This study was limited to patients with severe DME which previously had proved recurrent

\section{References}

1 American Diabetes Association. Data from the 2011 National Diabetes Fact Sheet. January 26, 2011. Accessed at: http: //www.diabetes.org/diabetes-statistics. jsp.

${ }^{2}$ Klein R, Klein BE, Moss SE, Davis MD, DeMets DL. The Wisconsin epidemiologic study of diabetic retinopathy. II. Prevalence and risk of diabetic retinopathy when age at diagnosis is less than 30 years. Arch Ophthalmol 1984; 102(4):520526. PMID: 6367724. or refractory to therapy. These results cannot be generalized to draw conclusions about the benefit of bevacizumab, pegaptanib, or dexamethasone for new onset diabetic macular edema.

\section{Conclusions}

Patients with intractable diabetic macular edema did not experience significant improvement in visual acuity after therapy with bevacizumab/dexamethasone or pegaptanib/dexamethasone. However, decreased central macular thickness was seen after both therapies. There was no significant difference in outcome measures between the two treatment groups. Intraocular pressure increased slightly after treatment, but no other adverse effects were experienced by any eyes in this study.

Further study is needed to confirm these conclusions, ideally a large randomized, blinded, controlled trial to compare the efficacy of pegaptanib and bevacizumab. Study also is needed to examine the effects of these treatments for new-onset DME, to define the long-term effects of treatment, and to quantify the effects of dexamethasone when combined with either pegaptanib or bevacizumab. Research is needed on new therapies for refractory diabetic macular edema which would improve visual acuity as well as preventing further damage.

3 Klein R, Klein BE, Moss SE, Davis MD, DeMets DL. The Wisconsin epidemiologic study of diabetic retinopathy. III. Prevalence and risk of diabetic retinopathy when age at diagnosis is 30 or more years. Arch Ophthalmol 1984; 102(4):527-532. PMID: 6367725.

4 Antcliff RJ, Marshall J. The pathogenesis of edema in diabetic maculopathy. Semin Ophthalmol 1999; 14(4):223-232. PMID: 10758223. 
5 Aroca PR, Salvat M, Fernández J, Méndez I. Risk factors for diffuse and focal macular edema. J Diabetes Complications 2004; 18(4):211-215. PMID: 15207838.

6 Pelzek C, Lim JI. Diabetic macular edema: Review and update. Opthalmol Clin North Am 2002; 15(4):555-563. PMID: 12550 87.

7 Davidson JA, Ciulla TA, McGill JB, Kles KA, Anderson PW. How the diabetic eye loses vision. Endocrine 2007; 32(1):107116. PMID: 17992608.

${ }^{8}$ Chen E, Looman M, Laouri M, et al. Burden of illness of diabetic macular edema: Literature review. Curr Med Res Opin 2010; 26(7):1587-1597. PMID: 20429823.

${ }^{9}$ Klein BE. Overview of epidemiologic studies of diabetic retinopathy. Ophthalmic Epidemiol 2007; 14(4):179183. PMID: 17896294.

${ }^{10}$ Klein R, Klein BE, Moss SE, Davis MD, DeMets DL. The Wisconsin epidemiologic study of diabetic retinopathy. IV. Diabetic macular edema. Ophthalmology 1984; 91(12):1464-1474. PMID: 6521986.

${ }^{11}$ Resnikoff S, Pascolini D, Etya'ale D, et al. Global data on vision impairment in the year 2002. Bull World Health Organ 2004; 82(11):844-851. PMID: 15640920.

${ }^{12}$ Photocoagulation for diabetic macular edema: Early Treatment Diabetic Retinopathy Study report number 1. Early Treatment Diabetic Retinopathy Study research group. Arch Ophthalmol 1985; 103(12):1796-1806. PMID: 2866759.

${ }^{13}$ Early photocoagulation for diabetic retinopathy. ETDRS report number 9. Early Treatment Diabetic Retinopathy Study Research Group. Ophthalmology 1991; 98(5 Suppl):766-785. PMID: 2062512.

${ }^{14}$ Schachat AP. A new look at an old treatment for diabetic macular edema. Ophthalmology 2008; 115(9):1445-1446. PMID: 18762072.
${ }^{15}$ Antonetti DA, Barber AJ, Khin S, Lieth E, Tarbell JM, Gardner TW. Vascular permeability in experimental diabetes is associated with reduced endothelial occludin content: Vascular endothelial growth factor decreases occludin in retinal endothelial cells. Penn State Retina Research Group. Diabetes 1998; 47(12):1953-1959. PMID: 9836530.

${ }^{16}$ Nauck M, Karakiulakis G, Perruchoud A, Papakonstantinou E, Roth M. Corticosteroids inhibit the expression of vascular endothelial growth factor gene in human vascular smooth muscle cells. Eur J Pharmacol 1998; 341(2-3):309-315. PMID: 9543253.

${ }^{17}$ Antonetti DA, Wolpert EB, DeMaio L, Harhaj NS, Scaduto RC Jr. Hydrocortisone decreases retinal endothelial cell water and solute flux coincident with increased content and decreased phosphorylation of occludin. J Neurochem 2002; 80(4):667667. PMID: 11841574.

${ }^{18}$ Edelman JL, Lutz D, Castro MR. Corticosteroids inhibit VEGF-induced vascular leakage in a rabbit model of blood-retinal and blood aqueous barrier breakdown. Exp Eye Res 2005: 80(2):249258. PMID: 15670803.

${ }^{19}$ Kuppermann BD, Blumenkranz MS, Haller JA, et al. Randomized controlled study of an intravitreous dexamethasone drug delivery system in patients with persistent macular edema. Arch Ophthalmol 2007; 125(3):309-317. PMID: 17353400.

${ }^{20}$ Haller JA, Kuppermann BD, Blumenkranz MS, et al. Randomized controlled trial of an intravitreous dexamethasone drug delivery system in patients with diabetic macular edema. Arch Ophthalmol 2010; 128(3):289-296. PMID: 20212197.

${ }^{21}$ Jonas JB, Kreissig I, Söfker A, Degenring RF. Intravitreal injection of triamcinolone for diffuse diabetic macular edema. Arch 
Ophthalmol 2003; 121(1):57-61. PMID: 12523885.

${ }^{22}$ Diabetic Retinopathy Clinical Research Network. A randomized trial comparing intravitreal triamcinolone acetonide and focal/grid photocoagulation for diabetic macular edema. Ophthalmology 2008; 115(9):1447-1459. PMID: 18662829.

${ }^{23}$ Lutty GA, McLeod DS, Merges C, Diggs A, Plouét J. Localization of vascular endothelial growth factor in human retina and choroid. Arch Ophthalmol 1996; 114(8):971-977. PMID: 8694733.

${ }^{24}$ Roberts WG, Palade GE. Increased microvascular permeability and endothelial fenestration induced by vascular endothelial growth factor. J Cell Sci 1995; 108(Pt 6):2369-2379. PMID: 7673356.

${ }^{25}$ US Food and Drug Administration. Label and Approval History. Nov 25, 2011. Accessed at: http://www.accessdata.fda. gov/drugsatnfda_docs/label/2009/125085s 0168lbl.pdf.

${ }^{26}$ Diabetic Retinopathy Clinical Research Network. A phase II randomized clinical trial of intravitreal bevacizumab for diabetic macular edema. Ophthalmology 2007; 114(10):1860-1867. PMID: 176981 96.

${ }^{27}$ Goyal S, Lavalley M, Subramanian ML. Meta-analysis and review on the effect of bevacizumab in diabetic macular edema. Graefes Arch Clin Exp Ophthalmol 2011; 249(1):15-27. PMID: 20665044.

${ }^{28}$ Ahmadieh H, Ramezani A, Shoeibi N, et al. Intravitreal bevacizumab with or without triamcinolone for refractory diabetic macular edema; a placebocontrolled, randomized clinical trial. Graefes Arch Clin Exp Ophthalmol 2008; 246(4):483-489. PMID: 17917738.

${ }^{29}$ Faghihi H, Roohipoor R, Mohammadi SF, et al. Intravitreal bevacizumab versus combined bevacizumab-triamcinolone versus macular laser photocoagulation in diabetic macular edema. Eur J Ophthalmol 2008; 18(6):941-948. PMID: 18988166.

${ }^{30}$ Soheilian M, Ramezani A, Obudi A, et al. Randomized trial of intravitreal bevacizumab alone or combined with triamcinolone versus macular photocoagulation in diabetic macular edema. Ophthalmology 2009; 116(6):1142-1150. PMID: 19376585.

${ }^{31}$ Lam DS, Lai TY, Lee VY, et al. Efficacy of 1.25 MG versus 2.5 MG intravitreal bevacizumab for diabetic macular edema: Six-month results of a randomized controlled trial. Retina 2009; 29(3):292299. PMID: 19287286.

${ }^{32}$ Goldberg RA, Flynn HW Jr, Isom RF, Miller D, Gonzalez S. An outbreak of streptococcus endophthalmitis after intravitreal injection of bevacizumab. Am J Ophthalmol 2012; 153(2):204-208. PMID: 22264943.

${ }^{33}$ Yamashiro K, Tsujikawa A, Miyamoto $\mathrm{K}$, et al. Sterile endophthalmitis after intravitreal injection of bevacizumab obtained from a single batch. Retina 2010; 30(3): 485-490. PMID: 19952993.

${ }^{34}$ Semeraro F, Morescalchi F, Parmeggiani F, Arcidiacono B, Costagliola C. Systemic adverse drug reactions secondary to antiVEGF intravitreal injection in patients with neovascular age-related macular degeneration. Curr Vasc Pharmacol 2011; 9(5):629-646. PMID: 21470108.

${ }^{35}$ US Food and Drug Administration. Label and Approval History. June 19, 2009. Accessed at: http://www.accessdata.fda. gov/drugsatfda_docs/label/2006/021756s0 06,s007lbl.pdf

${ }^{36}$ Cunningham ET Jr, Adamis AP, Altaweel $\mathrm{M}$, et al. A phase II randomized doublemasked trial of pegaptanib, an antivascular endothelial growth factor aptamer, for diabetic macular edema. Ophthalmology 2005; 112(10):1747-1757. PMID: 16154196. 
${ }^{37}$ Sultan MB, Zhou D, Loftus J, Dombi T, Ice KS, Macgen 1013 Study Group. A phase 2/3, multicenter, randomized, double-masked, 2-year trial of pegaptanib sodium for the treatment of diabetic macular edema. Ophthalmology 2011; 118(6):1107-1118. PMID: 21529957.

${ }^{38}$ Gragoudas ES, Adamis AP, Cunningham ET Jr, Feinsod M, Guyer DR, VEGF Inhibition Study in Ocular Neovascularization Clinical Trial Group. Pegaptanib for neovascular age-related macular degeneration. $\mathrm{N}$ Engl J Med 2004; 351(27):2805-2816. PMID: 15625332.

${ }^{39}$ Singerman LJ, Masonson H, Patel M, et al. Pegaptanib sodium for neovascular agerelated macular degeneration: Third-year safety results of the VEGF Inhibition Study in Ocular Neovascularisation (VISION) trial. Br J Ophthalmol 2008; 92(12):1606-1611. PMID: 18614570.

${ }^{40}$ D'Amico DJ, Masonson HN, Patel M, et al. Pegaptanib sodium for neovascular age-related macular degeneration: Twoyear safety results of the two prospective, multicenter, controlled clinical trials. Ophthalmology 2006; 113(6):992-1001. PMID: 16647134.

${ }^{41}$ Parravano M, Menchini F, Virgili G. Antiangiogenic therapy with anti-vascular endothelial growth factor modalities for diabetic macular oedema. Cochrane Database Syst Rev 2009; (4):CD007419. PMID: 19821414.
${ }^{42}$ Holladay JT. Proper method for calculating average visual acuity. J Refract Surg 1997; 13(4):388-391. PMID: 9268940.

${ }^{43}$ Alkuraya H, Kangave D, Abu El-Asrar AM. The correlation between optical coherence tomographic features and severity of retinopathy, macular thickness and visual acuity in diabetic macular edema. Int Ophthalmol 2005; 26(3):93-99. PMID: 17063373.

${ }^{44}$ Fitzmaurice GM, Laird NM, Ware JH. Applied longitudinal analysis. Hoboken, NJ: Wiley, 2004. ISBN: 0471214876.

${ }^{45}$ Singer JD, Willett JB. Applied longitudinal data analysis: Modeling change and event occurrence. New York: Oxford University Press, 2003. ISBN: 0195152964.

${ }^{46}$ Lindsey JK. Models for Repeated Measurements. Oxford: Clarendon Press; 1993. ISBN: 0-19-852299-1.

${ }^{47}$ Yeh WS, Haller JA, Lanzetta P, et al. Effect of the duration of macular edema on clinical outcomes in retinal vein occlusion treated with dexamethasone intravitreal implant. Ophthalmology 2012; 119(6): 1190-1198. PMID: 22361318.

${ }^{48}$ Gonzalez S, Rosenfeld PJ, Stewart MW, Brown J, Murphy SP. Avastin doesn't blind people, people blind people. Am J Ophthalmol 2012; 153(2):196-203. PMID: 22264942.

Keywords: diabetic retinopathy, macular edema, pegaptanib, bevacizumab 